\title{
ON DIFFERENT CONCEPTS OF CLOSEDNESS OF LINEAR OPERATORS
}

\author{
SanaA Messirdi, BeKKai Messirdi And Miloud Messirdi
}

\begin{abstract}
The purpose of this paper is to introduce, by means of the extensions of almost closed operators, the notion of almost closable linear operator acting in a Hilbert or Banach space. This class of operators is strictly included in the class of all unbounded linear operators, it contains the set of all closable operators and that of all almost closed operators and is invariant under finite and countable sums, finite products, limits and integrals. We also present some fundamental properties relative to almost closability and we define a locally convex Hausdorff topology in the set of all almost closable operators.
\end{abstract}

Mathematics subject classification (2010): 47A05, 47B33.

Keywords and phrases: Almost closed extensions, almost closable operators, sums, products, limits, integrals, locally convex Hausdorff topology.

\section{REFERENCES}

[1] S. Agmon And L. Nirenberg, Properties of solutions of ordinary differential equations in Banach space, Comm. Pure Appl. Math. 16, (1963), 121-239.

[2] W. ARENDT, Vector valued Laplace transforms and Cauchy problems, Israel J. Math. 59, (1987), 327-352.

[3] A. Azzouz, B. Messirdi And G. Djellouli, New results on the closedness of the product and sum of closed linear operators, Bull. Math. Anal. Appl. 3, 2 (2011), 151-158.

[4] B. BAUMER AND F. NEUBRANDER, Laplace transform methods for evolution equations, Conferenze del Seminario di Matematica dell' Universita di Bari 259, (1995), 27-60.

[5] S. R. CARAdus, Semiclosed operators, Pacific J. Math. 44, 1 (1973), 75-79.

[6] J. Dixmier, L'adjoint du produit de deux opérateurs fermés, Ann. Fac. Sci. Toulouse Math. 4ème série, 11, (1974), 101-106.

[7] G. Djellouli, S. Messirdi And B. Messirdi, Some stronger topologies for closed operators in Hilbert space, Int. J. Contemp. Math. Sciences 5, 25 (2010), 1223-1232.

[8] R. ENGEL AND K. J. NAGEL, One-parameter semigroups for linear evolution equations, Graduate Texts in Mathematics. Springer Verlag, 2000.

[9] M. Fernandez Miranda And J. Ph. Labrousse, On the closure of the product and sum of linear relations, Complex Anal. Oper. Theory 6, 3 (2012), 613-624.

[10] P. A. Fillmore And J. P. Williams, On operator ranges, Adv. Math. 7, (1971), 254-281.

[11] C. FoIAS, Invariant semiclosed subspaces, Preprint, Institute of Mathematics, Bucarest, Romania, 1970.

[12] E. Hille And R. S. Phillips, Functional Analysis and Semi-Groups, Amer. Math. Soc. Providence, Rhode Island, 1957.

[13] R. V. KADILON AND J. R. Ringrose, Fundamentals of the theory of operator algebras (I), Acad. Press, 1983.

[14] T. Kato, Perturbation Theory for Linear Operators, Springer-Verlag, Berlin, 1995. Reprint of the 1980 edition.

[15] W. E. KaUfman, Representing a closed operator as a quotients of continuous operators, Proc. Amer. Math. Soc. 72, (1978), 531-534.

[16] W. E. Kaufman, Semiclosed operators in Hilbert space, Proc. Amer. Math. Soc. 76, (1979), 67-73.

[17] J. Ph. LABRousse, Les opérateurs quasi Fredholm: Une généralisation des opérateurs semi Fredholm, Rend. Circ. Mat. Palermo (2) Suppl. Tomo XXIX, (1980), 161-258. 
[18] J. Ph. LABrousse And B. Mercier, Equivalences compactes entre deux opérateurs fermés sur un espace de Hilbert, Math. Nachr. 133, (1987), 91-105.

[19] J. S. MAC NEARNEY, Investigation concerning positive definite continued fractions, Duke Math. J. 26, (1959), 663-678.

[20] I. V. Melnikova And A. Filinikov, Abstract Cauchy problems: Three approaches, Chapman and Hall/CRC Monographs ans Surveys in Pure and Applied Mathematics. Boca, Raton, London, New York, Washington, D.C., 2001.

[21] B. Messirdi, M. H. Mortad, A. Azzouz and G. Djellouli, A Topological Characterization of the Product of Two Closed Operators, Colloq. Math. 112, 2 (2008), 269-278.

[22] B. Messirdi And M. H. Mortad, On Different Products of Closed Operators, Banach J. Math. Anal. 2, 1 (2008), 40-47.

[23] S. Messirdi, M. DjaA And B. Messirdi, Stability of Almost Closed Operators on a Hilbert Space, Sarajevo J. Math. 5, 17 (2009), 133-141.

[24] M. Polakovic And Z. Riecanova, Generalized effects algebras of positive operators densely defined on Hilbert spaces, Int. J. Theor. Phys. 50, (2011), 1167-1174. 